\title{
Quality and Quality Improvement
}

\section{Quality of Health Care: The Views of Homeless Youth}

\author{
Josephine Ensign
}

Objective. To develop homeless-youth-identified process and outcome measures of quality of health care.

Data Sources/Study Setting. Primary data collection with homeless youth from both street and clinic settings in Seattle, Washington, for calendar year 2002.

Study Design. The research was a focused ethnography, using key informant and indepth individual interviews as well as focus groups with a purposeful sample of 47 homeless youth aged 12-23 years.

Data Collection/Extraction Methods. All interviews and focus groups were taperecorded, transcribed, and preliminarily coded, with final coding cross-checked and verified with a second researcher.

Principal Findings. Homeless youth most often stated that cultural and interpersonal aspects of quality of care were important to them. Physical aspects of quality of care reported by the youth were health care sites separate from those for homeless adults, and sites that offered a choice of allopathic and complementary medicine. Outcomes of health care included survival of homelessness, functional and disease-state improvement, and having increased trust and connections with adults and with the wider community.

Conclusions. Homeless youth identified components of quality of care as well as how quality of care should be measured. Their perspectives will be included in a larger follow-up study to develop quality of care indicators for homeless youth.

Key Words. Homeless youth, quality of care, qualitative research, primary care

Homeless youth are a medically underserved and vulnerable population in the United States. Based on recent research using a nationally representative sample of U.S. households, homelessness in adolescents ages 12-17 is more common than for adults (Ringwalt et al. 1998). In the United States and worldwide, communities commit resources and policies to address the problems and the needs of homeless youth, but comparatively few resources are placed on attempts to evaluate the impact of these policies and programs on the lives of homeless youth. Having ways to measure quality of care for homeless youth can help health programs establish performance monitoring 
in order to test and refine approaches to health care provision. Since homeless youth are more vulnerable and at-risk for negative health, improved quality of care for homeless youth has the potential for greater pay-off than for other groups of adolescents.

Adolescents in general have unique barriers to access of appropriate health care and exhibit poor patterns of preventive primary health care (Wienick, Weiger, and Cohen 1998). Adolescents face barriers to health care including confusion over ability to legally consent for their own care, concerns over confidentiality of care, office hours that conflict with school, and discomfort with traditional adult-oriented health care settings (Klein et al. 1999). Of all age groups in this country, adolescents (including young adults) are the most likely to be uninsured or underinsured (English and Morreale 2003).

Homeless people, including adults and adolescents, are characterized as having inadequate access to primary health care, and as seeking care at emergency departments (EDs) only after they are no longer able to ignore their health condition (Geber 1997; Institute of Medicine 1998). Being homeless creates health problems and makes health care more difficult to obtain, especially since basic needs such as food and shelter take priority over health care (Gelberg 1997; Zerger 2002). Homeless youth have greater problems with access to care than do homeless adults or nonhomeless adolescents, including a more profound lack of insurance/payment source, greater anxiety over confidentiality, more confusion over ability to consent for their own care, and less tolerance of lengthy waiting times and intake forms (Ensign and Gittelsohn 1998; Klein et al. 2000). An important and often overlooked factor in homeless youth access to care is that they do not have an adult to help them navigate the increasingly complex health care system. While the main structural factors of health care affecting access to care are known for homeless youth, the process and outcome factors are not well established.

Measuring quality of health care has become a major focus of health services research in the United States. It is viewed as an essential step in improving the health of our population, in containing the rise in health care expenditures, and in increasing consumer confidence in the health care

\footnotetext{
Support for the research for this article came from the Agency for Health Care Research and Quality grant no. HS11414-02. Views expressed in this article are the sole responsibility of the author and are not those of the funding agency.
}

Address correspondence to Josephine Ensign, F.N.P., Dr.P.H., Associate Professor, Department of Psychosocial and Community Health, University of Washington, Box 357263, Seattle, WA 98195. 
system (Department of Health and Human Services 1998). However, research on quality of care measures including outcomes for pediatric and adolescent health has lagged behind that for adults (McGlynn and Halfon 1998), as has that for underserved populations in general (Beltran 2000). A criticism of outcomes research is that it relies on research "experts" to define which outcomes are important and does not include consumer perceptions or definitions of desired outcomes (Ray 1999). Youth in particular are rarely considered to be experts about their own health needs and priorities, yet health programs that include youth throughout their design, implementation, and evaluation are more likely to be effective (World Health Organization 1997). There are no quality of care measures for adolescents that include youth-identified measures of quality, as well as no quality of care measures specific to homeless young people.

To improve health care access and quality of health care services specific to homeless youth, valid performance measures need to be developed. The purpose of this study was to develop homeless-youth-identified process and outcome measures of quality of health care using qualitative methods.

\section{METHODS}

\section{Population and Setting}

The study was conducted in a homeless youth clinic and two street locations in Seattle, Washington. Based on recent survey results, there are an estimated 500-1,000 street and shelter-based youth (ages 12-24) in Seattle on any given night, and when including "near homeless youth" such as "couch surfers" (young people doubling up with friends or lovers) and foster care youth between placements, the number is close to 2,000 (Shaw 2000). The homeless youth clinic, where clinic-based data were collected, targets homeless and atrisk youth aged 12-23 years. It currently provides health care for the largest number of homeless youth in Seattle, serving 2,006 youth in 2002. For 2002, the clinic population was 64 percent female, 76 percent Caucasian (11 percent African American, 4 percent American/Alaskan Indian, 4 percent mixed race, 2 percent Hispanic, 1 percent Asian), and the average age was 19 years.

The two street-based areas of Seattle included as study sites were the University District in North Seattle, and the Broadway/Capitol Hill area in Central Seattle. These two areas have long been popular areas for homeless and other street-involved youth to congregate. Data collection was facilitated by working with the staff of a medical van that serves homeless youth in these 
areas. The van is a medically equipped mobile home that provides streetbased medical care for homeless youth aged 12-23 in the evening and early morning hours at the University and Capitol Hill districts of Seattle two evenings a week. For calendar year 2002, the medical van provided care for 417 homeless youth, with 60 percent being male, average age 20, and 59 percent Caucasian (27 percent unknown, 4 percent American/Alaskan Indian, 4 percent mixed race, 3 percent Hispanic, 2.5 percent African American, 0.5 percent Asian). The medical van operates in tandem with a smaller outreach van and staff who provide food, clothing, blankets, and referrals to shelters for homeless youth seven nights a week.

\section{Data Collection and Sampling}

The study design was descriptive, using focused ethnographic methodology including key informant and semistructured interviews, as well as focus groups. This was part of a larger study that included participant observations to describe the illness experiences of homeless youth, which is described elsewhere (Ensign and Bell, in press). The study took place from January 2002 to December 2002 in Seattle, Washington. The sampling was purposive, with the investigator (PI) seeking equal numbers of clinic and street-based youth, as well as equal numbers of male and female youth, younger and older than age 18. The age, gender, and site location groups were chosen based on results of previous surveys suggesting that youth in these groups had different issues accessing services. Verbal consent was obtained from all youth, with information statements signed by the researcher. The Committee for Human Research at the University of Washington approved the research plan.

All data were collected by the PI, a Caucasian female nurse practitioner researcher in her forties who has more than 15 years of experience in providing health care and in conducting qualitative and mixed-method research with homeless youth, with eight of these years being in Seattle. During the time of the current research, the PI was not the health care provider for any of the homeless youth research participants. Three different data collection methods were used in this study, including the following:

Key Informant Interviews. Two key informants were chosen for participation in the research and were available throughout the entire research period. One was male and one was female, both were in their mid-twenties and had experience being homeless as an adolescent, but were now stabilized in their living situations. The PI interviewed the key informants at least once a month throughout the research period for a total of 30 interviews. The key informants 
helped to clarify unfamiliar terms used and situations described by the homeless youth, as well as to add their perspectives on the emerging themes from the semistructured interviews and focus groups with the youth.

Semistructured Intervieres. Research participants were chosen for inclusion based on their experience with seeking health care while homeless and on their willingness to talk about these experiences. None of the youth from the street-based site were seeking care on the medical van, but were using the smaller van's services of food and clothing. Youth were recruited and interviewed until saturation of responses occurred (Morse 2000). The final sample for the interviews was 30 young people with a mean age of 20 years (range 12-23 years). The racial/ethnic mix of the young people in the present study was close to that of the clinic and medical van population overall $(80$ percent white, 13 percent African American, 7 percent Hispanic/mixed race).

The interviews covered the topic of quality of primary health care with their perspectives on what "ingredients" were necessary for the provision of quality health care for homeless youth, how to measure these ingredients, and how health care providers can "know when they have done a good job." In addition, youth were asked for their recommendations for ways of measuring these aspects of quality of care. The interviews lasted 30-45 minutes each. All data were collected by the PI during regular clinic evening hours (6:00-9:00 P.M.), as well as on the streets during van outreach hours (9:30 P.M.-2:00 A.M.). Only youth who identified themselves as currently being homeless, within the age range of 12 to 23 years, and English-speaking were included in the study. There are very few non-English-speaking homeless youth at either site; none were present on the nights of the research. For the purpose of this research, "homeless" was defined as "staying in a temporary shelter, in a public place such as a park, under a bridge, in a car, or other similar place." A male outreach worker from each site who knew the youth well assisted with initial recruitment on the evenings of the data collection. There were no youth refusals for those approached for the study and who met inclusion criteria.

The interviews were conducted by the PI in a private consulting room in the clinic or street-based in the front seats of the medical van. After permission from the research participants, all individual interviews were tape-recorded. Youth who completed the interview received a $\$ 10$ prepaid phone card as compensation for their time.

Focus Groups. After the interviews were complete and had been preliminarily analyzed, focus groups were conducted for more in-depth exploration of identified themes and topics. Two mixed-gender focus groups were conducted, one each at the clinic and on the medical van for a total of 15 
youth. The sampling for the focus groups was purposive, with an attempt made to include an equal number of both genders, as well as those younger and older than age 18 . The clinic focus group was held in a private meeting room upstairs from the main clinic. The focus group on the van was conducted during regular van outreach hours, but on a night when regular medical care was not being provided. Both groups included different youths from those interviewed or in the other focus groups (no duplicates). The groups had an average age of 20 years (range 16-23 years). For focus groups, the PI was assisted by a Caucasian male anthropologist in his twenties who served as recorder for the group process. The focus groups followed a standard focus group format, lasted an hour each, and were tape-recorded. Youth who completed a focus group received a $\$ 10$ prepaid phone card along with snacks and milk as compensation for their time.

\section{Data Management and Analyses}

Tape-recordings of all interviews and focus groups were transcribed by an experienced transcriptionist, and were entered into the Atlas-t $i$ qualitative data analysis software (Muhr 1997). The PI completed descriptive and analytic coding of the interviews and focus groups and checked them for inconsistencies. After the PI completed initial coding, the male research assistant cross-checked, validated, and refined the coding in conjunction with the PI. Summaries of the research were validated and refined by crosschecking the results with the original individuals from whom the information was obtained, as well as with the key informants. Qualitative data management and analysis followed standard ethnographic techniques, and included latent and manifest content analyses, and frequency tabulations. For latent content analyses, passages within individual interviews or focus group discussions were reviewed within the context of the entire interview in order to determine the major theme or significant meaning. Manifest content analyses followed latent content analyses, and consisted of searching all transcripts for certain words or terms, tabulating them, and then conducting frequency tabulations.

\section{FINDINGS}

\section{Cultural Aspects of Health Care Quality}

The youths stated that health care services that take into account the lives of homeless youth were the most useful to them. A major theme in the interviews 
with the youth was of the importance of cultural competency of providers, and how providers could tailor their health care advice and interventions to the realities of life for homeless youth.

When people at the clinics have an understanding of the homeless situation, of knowing where we're coming from, how we're living and dealing with being homeless as best we can...-that's what helps. Then they can do everything possible in their power to help us be as healthy as possible even while we're out on the streets. (18-year-old white male, focus group on streets)

An additional cultural aspect of health care quality that was stated by most youth was an understanding on the part of providers as to the attitudes of homeless youth. Many talked of how difficult it was to be homeless and take care of themselves, and how they had histories of conflict-laden relationships with various adults in their lives. They said that their past lives and present circumstances made it difficult for them to be able to trust adults, including health care providers. One young man summed it up this way:

Some of us out here are kind of buttholes, the homeless kids I mean. But you'll find that the more you treat a person with respect out here, the more that assholeness goes away, because we kind of put up these big shields and whatnot to protect ourselves. (23-year-old white male, interview on streets)

A recurring theme throughout the interviews and focus groups was that of the value of health care in the lives of the homeless youth. Many of the youth said that while they often neglected health issues, they viewed health care as "incredibly important, it's one of the basic needs. You need food, you need shelter, and you need health care" (20-year-old African American woman, interview on the streets).

\section{Interpersonal Aspects of Health Care Quality}

Interpersonal factors in the health care encounter were among the most frequently mentioned by the youth along with the cultural aspects previously mentioned. The youth talked about the importance of being treated with respect by health care providers.

It helps when people in health care don't judge us, and aren't stuck up. ... They see you as a human being, and not as a dirty street kid. Whether you got ambition or no ambition, no matter what your situation is, you feel welcome. (21-year-old white male, interview on streets) 
The youth also stated that other aspects of good communication skills are important components of quality of care for homeless youth. "When they talk so I can understand what they're saying" was a representative comment. Additionally, youth emphasized the fact that providers were more effective when they did not have a lecturing tone of voice, "inform me, talk to me like a regular person instead of telling me what to do." Youth frequently stated that continuity of care was an important component of quality of care, in that they could develop a relationship and rapport with one provider, and "not have to start all over again with repeating my story to someone else." As part of the interpersonal communication aspect of quality health care, many of the youth stated that health education, including information on health insurance and how to navigate the health care system were especially important for homeless youth.

It's especially important for street kids. We need it on a more personal level since we don't have family to tell us this stuff. Health education helps the most because we can turn around and educate our friends and peers, and then that knowledge just spreads. (23-year-old white male, focus group on streets)

Finally, youth stated that an important component of quality of health care services included ongoing encouragement for them to provide feedback to the clinic and providers about service gaps and performance issues. Youth in both focus groups brought this up as a positive aspect of care and linked it with the clinic and health van "sponsoring" the focus group research to get additional input from the youth.

When they ask us what we think about things, like both positive and negative feedback, and are constantly fine-tuning what they're doing to help us. That feels good and it makes the services more what we need. (18-year-old white male, focus group in clinic)

\section{Physical Aspects of Health Care Quality}

One of the main physical aspects of health care quality that was talked about often by the youth was location of the clinics. Youth consistently reported that they wanted health care delivered in sites separate from those for older homeless people. Their reason for this was because they felt intimidated by the "old drunks and homeless bums." This issue was unanimously voiced by the homeless female youth in the study, but also by the majority of homeless male youth. 
Youth in this study also viewed a component of quality of care being clinics that include complementary medicine on site along with more traditional allopathic services. Many youth said that their homeless friends were more willing to go for health care first from complementary medicine such as naturopathy or acupuncture, and later would be willing to be seen by allopathic providers who were co-located in the same clinic.

\section{Technical Aspects of Health Care Quality}

Technical aspects of quality of care were mentioned least often by the youth in this study. Several technical aspects that were talked about in both focus groups were when providers appeared confident in giving injections, as well as in performing pelvic exams, most often assessed by the youth as causing "the least pain possible."

\section{Outcomes of Health Care}

The majority of youth said that improvement in health and functional status was one of the most important desired outcomes of health care. "So we're not in a lot of pain and can get around and do what we need to do" was a representative comment. In both focus groups, the youth linked this improvement in health and functional status to enabling them to get out of homelessness, "You can't keep a job and get a place of your own if your health sucks." Youth also frequently mentioned outcome measures of improvements in certain common health conditions for homeless youth, including nutritional status ("weigh us so you know we're not loosing a ton of weight from not getting enough food"), mental health ("see if our mood and personality improves"), as well as overall reductions in pregnancies and sexually transmitted diseases. Additionally, many youth said that "surviving homelessness" was an important outcome of health care for homeless youth.

Youth consistently stated that desired outcomes of health care for homeless youth were more global in nature, and included fostering a sense of purpose in life and connectedness to the wider community. They talked about positive health care experiences helping them to be able to trust adults and to make positive changes in other areas of their lives.

Happy healthy kids, basically, that's how you can know that health care works. And you can tell they're happy and healthy by the smile on their face, and they've gotten clean and off the streets and come back to volunteer on the van or something. You know, we get healthy enough that we can give back to people who helped us and help other kids get out of the situation as well. (18-year-old white male, focus group interview on streets) 


\section{Conceptual Links and Suggested Measures}

Conceptual links between process and outcome indicators of quality of health care made by the youth were the strongest for a combination of the cultural and interpersonal skills of providers and clinics with the outcome of a greater sense of trust in adults and connection with the wider community. The ideal situation described by many youth in the interviews was of having a health care "home" with a clinic and provider attuned to the realities of homeless youth, where they felt respected, listened to, and taken care of over a period of months or years until they could get out of homelessness and into a more stable situation. Many of the youth also talked of this ideal situation as health care being one component of a network of connected and coordinated service providers helping them with interrelated needs such as shelter, food, education, and life skills training.

Homeless youth in this study suggested measures of quality of care that included surveys of homeless youth for their perceptions of access to and quality of the health care encounter, as well as for their improvements in functional status, symptoms of disease, and increase in trust and connections with adults and the community. In focus groups, the youth said that they thought such surveys would be well accepted by homeless youth as long as they were easy to understand, were not more than two to three pages in length, and the purpose of the form was clearly stated. The young people interviewed also said that physiologic measurements for improvements in disease status, as well as "what's in our charts" for trends in diagnoses for homeless youth, were important ways of monitoring the performance of health care for homeless youth.

\section{DISCUSSION}

The results of this study provide homeless youth perspectives on the main measures of quality of care. Although youth were not asked to rank the importance of process measures of quality of care, cultural and interpersonal aspects of health care quality were the most often mentioned by youth. This finding reinforces the need to increase staff training on cultural competency specific to the special circumstances of homeless youth. Based on the reports of the homeless youth in this research, it is important to include in such staff training an awareness and sensitivity to the fact that the youth's often-difficult attitudes can be a protective mechanism due to previous abusive interactions with adults. An important component of trust-building within the health care 
relationship as identified by the youth was that of continuity of care with a primary provider. While continuity of care probably is important to nonhomeless youth and to homeless adults, it is likely to be even more essential for the provision of quality of care for homeless adolescents.

The physical aspects of quality of care of having clinics separate from those for homeless adults and providing a choice of allopathic and complementary medicine can be used for planning or improving existing health care programs for homeless youth. Complementary health care services appear to be less intimidating to many of the homeless youth than allopathic medicine, and may serve as an important bridge to needed allopathic care. Homeless youth in Seattle have been found to have high rates of use and acceptance of complementary medicine (Breuner, Barry, and Kemper 1998). Although there may be important regional differences in homeless youth acceptance of complementary medicine, each locale can find other nonallopathic services desired by their homeless youth, which could serve the same purpose. Technical aspects of quality of care were mentioned least often by the youth in this study, which is consistent with the literature, in that consumers are not likely to feel competent in assessing technical components of care (Patrick 1997).

Not surprisingly, the main outcomes of quality of health care reported by the youth in this study were improvement in functional status and disease states, as well as surviving homelessness. The limited data that exist on mortality rates for homeless adolescents indicate that the rates are much higher than for nonhomeless adolescents (Switchboard 2003), making survival a reasonable outcome measure of health care for homeless youth. The young people in this study also made a strong connection between appropriate health care improving their functional status that in turn allowed them to make the necessary changes to move out of homelessness into more stable lifestyles. Although similar studies in the published literature were not found for homeless adults, it is likely that they would value similar outcomes of health care.

The more global outcome of quality of health care of increased trust and connections with adults and the community is important to consider for monitoring performance of health care for homeless youth. While many people may argue that this is an outcome outside the control of health care, the homeless youth make definite conceptual connections between the cultural and interpersonal process indicators of care and this outcome of health care. Many youth widened the outcome to be connections and continuity within a network of social supports for homeless youth; this points to the need for 
further research into how to measure these community connections. This outcome of health care is probably more important to homeless youth than to their nonhomeless peers who are more likely to have other avenues for community connectedness through school and family.

This study was limited to the views of homeless youth from a clinic and two street settings in Seattle, Washington, in which all of the youth were seeking health care or basic street outreach services. Therefore, differences may exist for Seattle homeless youth who do not access services at these sites, as well for homeless youth from other cities in the United States, or from rural locations. The young people in this study represent the average age of the clinic and medical van population (age 19), but important differences may exist for homeless youth in younger age groups. The fact that the PI was also involved in the provision of health care for homeless youth introduces potential bias. However, this bias was minimized by triangulating methods, data sources, and researchers, and by cross-checking results with original informants.

An increasing number of clinics for homeless youth are in operation throughout the United States and other countries, with a cadre of "street care specialists" experienced in providing appropriate health and social care to this vulnerable population. Future areas of research include developing national guidelines for the provision of quality health care for homeless youth, drawing on expert consensus as well as on homeless youth consensus from a national sample. Homeless youth are the main stakeholders in quality of care and should have input into what measures of quality should be.

\section{REFERENCES}

Beltran, R. 2000. "Underserved Populations: The Quality of Their Health Services." American Journal of Medical Quality 15 (4): 125.

Breuner, C. C., P. J. Barry, and K. J. Kemper. 1998. "Alternative Medicine Use by Homeless Youth." Archives of Pediatric and Adolescent Medicine 152 (11): 1071-5.

Department of Health and Human Services. 1998. "The Challenge and Potential for Assuring Quality Health Care for the 21st Century, Publication No. OM 980009." Washington, DC: Department of Health and Human Services for the Domestic Policy Council. Available at http//:www.ahcpr.gov/qual/21stcena. htm.

English, A., and M. Morreale. 2003. "Health Insurance for Adolescents: What Is Happening?" Paper presented at the Society for Adolescent Medicine, Seattle, WA. 
Ensign, J., and M. Bell. (in press). “Illness Experiences of Homeless Youth.” Qualitative Health Research.

Ensign, J., and J. Gittelsohn. 1998. "Health and Access to Care: Perspectives of Homeless Youth in Baltimore City, USA.” Social Science and Medicine 47 (12): 2087-99.

Geber, G. 1997. "Barriers to Health Care for Street Youth.” Journal of Adolescent Health 21 (5): 287-90.

Gelberg, L. 1997. "Competing Priorities as a Barrier to Medical Care among Homeless Adults in Los Angeles." American Journal of Public Health 87 (2): 217-20.

Institute of Medicine. 1998. Homelessness, Health, and Human Needs. Washington, DC: National Academy Press.

Klein, J. D., K. M. Wilson, M. McNulty, C. Kapphahn, and K. S. Collins. 1999. “Access to Medical Care for Adolescents: Results from the 1997 Commonwealth Fund Survey of the Health of Adolescent Girls.” Journal of Adolescent Health 25 (2): 120-30.

Klein, J. D., A. H. Woods, K. M. Wilson, M. Prospero, J. Greene, and C. Ringwalt. 2000. "Homeless and Runaway Youths' Access to Health Care." Journal of Adolescent Health 27 (5): 331-9.

McGlynn, E., and N. Halfon. 1998. "Overview of Issues in Improving Quality of Care for Children." Health Services Research 33 (4): 977-1000.

Morse, J. 2000. “Determining Sample Size.” Qualitative Health Research 10 (1): 3-5.

Muhr, T. 1997. Atlas-ti. Berlin: Scientific Software Development.

Patrick, D. L. 1997. "Finding Health-Related Quality of Life Outcomes Sensitive to Health-Care Organization and Delivery." Medical Care 35 (11): NS49-57.

Ray, L. 1999. "Evidence and Outcomes: Agendas, Presuppositions, and Power." Journal of Advanced Nursing 30 (5): 1017-26.

Ringwalt, C. L., J. M. Greene, M. Robertson, and M. McPheeters. 1998. "The Prevalence of Homelessness among Adolescents in the United States." American Journal of Public Health 88 (9): 1325-9.

Shaw, M. 2000. Addressing the Needs of Homeless Youth in Seattle/King County. Seattle, WA: City of Seattle Human Services Department, Family and Youth Services Division.

Switchboard, N. R. 2003. "National Runaway Switchboard Media Information Kit" [accessed June 4, 2003]. National Runaway Switchboard. Available at http:// www.nrscrisisline.org.

World Health Organization. 1997. Youth Friendly Health Services: A Review of Programmes and Lessons Learned. Geneva: Switzerland.

Wienick, R. M., M. E. Weiger, and J. W. Cohen. 1998. "Children's Health Insurance, Access to Care, and Health Status: New Findings." Health Affairs 17 (2): 127-36.

Zerger, S. 2002. "Chronic Medical Illness and Homeless Individuals. National Health Care for the Homeless Council" [accessed on September 15, 2003]. Available at http//:www.nhchc.org/publications/literaturereview_chronicillness.pdf. 
